\title{
Renal Ultrasound
}

National Cancer Institute

\section{Source}

National Cancer Institute. Renal Ultrasound. NCI Thesaurus. Code C159885.

The use of ultrasound to image the kidney. 